\title{
Avaliação de Programas de Microcrédito do Banco do Nordeste
}

Alcides Fernando Gussi ${ }^{1}$ Gláucia Furtado Brasil de Almeida²

Rita Josina Feitosa da Silva ${ }^{3}$

Raul da Fonseca Silva Thé ${ }^{4}$ Janainna Edwiges de Oliveira Pereira ${ }^{5}$

1 Professor e coordenador do Mestrado em Avaliação de Políticas Públicas - MAPP/Universidade Federal do Ceará - UFC.

2 Técnica do Banco do Nordeste e Mestre em Avaliação de Políticas Públicas/MAPP/UFC.

3 Técnica do Banco do Nordeste e Mestre em Avaliação de Políticas Públicas/MAPP/UFC.

4 Graduando em Ciências Sociais - UFC e bolsista de Iniciação Científica PIBIC/CNPq.

5 Graduanda em Ciências Sociais- UFC e bolsista de Iniciação Científica PIBIC/UFC. 


\section{Resumo}

ESTE ARTIGO TRATA-SE DE UMA AVALIAÇÃO DE DOIS PROGRAMAS DE MICROCRÉDITO DO BANCO DO NORDESTE DO BRASIL, DIFERENTEMENTE TIPIFICADOS NO CAMPO DAS MICROFINANÇAS: O CREDIAMIGO, TIPO DE MICROCRÉDITO PRODUTIVO ORIENTADO, E O Programa de Apoio a Projetos Produtivos Solidários (PAPPS), ouve financia Fundos ROTATIVOS SOLIDÁRIOS (FRS), UM TIPO DE MICROFINANÇAS SOLIDÁRIAS. A METODOLOGIA ESTÁ CENTRADA NA ETNOGRAFIA, OUUE PERMITE APREENDER AS REPRESENTAÇÕES, A VISÃO DE MUNDO E A PERSPECTIVA DOS ATORES ENVOLVIDOS NESSES PROGRAMAS. OS RESULTADOS DA PESOUISA APONTAM PARA DIFERENTES IMPACTOS DOS PROGRAMAS NA RENDA DOS BENEFICIÁRIOS, MAS TAMBÉM OQUANTO A DIMENSÕES SOCIAIS E POLÍTICAS: O CREDIAMIGO PROMOVE A INSERÇÃO DE TRABALHADORES INFORMAIS NO MERCADO; E O PAPPS FOMENTA JUNTO AOS BENEFICIÁRIOS VALORES ECONÔMICOS E POLÍTICOS PRÓXIMOS AO DA ECONOMIA SOLIDÁRIA. A AVALIAÇÃO FOI DESENVOLVIDA NO NÚCLEO Multidisciplinar de Avaliação de PolíTICAS PÚBlicas (NUMAPP) do MESTRAdO em Avaliação de Políticas Públicas (MAPPIUFC) POR UMA EQUUIPE INTEGRADA POR ALUNOS E FUNCIONÁRIOS DO BANCO DO NORDESTE.

\section{Abstract}

THIS PAPER IS AN EVALUATION OF TWO DIFERENTS MICROCREDIT PROGRAMS OF BANCO DO NORDESTE: CREDIAMIGO, A TYPE OF PRODUCTIVE MICROCREdit and the Programa de Apolo a Projetos PRODUTIVOS SOLIDÁRIOS (PAPPS), THAT FINANCES THE Fundos ROtativos SOLIDÁRIOS (FRS), A TYPE OF SOLIDARITY MICROFINANCE. THE EVALUATION METHODOLOGY IS FOCUSED ON ETHNOGRAPHY, WHICH ALLOWS THE REPRESENTATIONS, THE VIEWPOINT AND THE PERSPECTIVES OF THE ACTORS INVOLVED IN THESE PROGRAMS. THE RESEARCH RESULTS INDICATE TO DIFFERENT IMPACTS OF THE PROGRAMS ON THE INCOME OF BENEFICIARIES, BUT ALSO AS SOCIAL AND POLITICAL DIMENSIONS: CREDIAMIGO APPROACHES AN INTEGRATION OF INFORMAL WORKERS IN THE MARKET, AND THE PAPPS REINFORCES THE POLITICAL AND ECONOMIC VALUES OF THE SOLIDARITY ECONOMY. THE RESEARCH WAS DEVELOPED FROM THE Núcleo Multidisciplinar de Pesquisa (NUMAPP), Master Avaliação de Políticas Públicas da UNIVERSIDADE FEDERAL DO CEARÁ COMPOSES THE STUDENTS AND EMPLOYEES OF BANCO DO NORDESTE.

\section{PALAVRAS-CHAVE:}

Avaliação; Políticas públicas; Microcrédito; Economia Solidária; Banco do Nordeste

Revista Brasileira de Monitoramento e Avaliação | Número 6 | Julho-Dezembro de 2013

Avaliação de Programas de Microcrédito do Banco do Nordeste 


\section{Introdução}

O presente artigo $^{6}$ resulta de uma pesquisa, vinculada ao Núcleo Interdisciplinar de Pesquisa do Mestrado em Avaliação de Políticas Públicas (NUMAPP) da Universidade Federal do Ceará (UFC), que realizou uma avaliação dos programas de microcrédito, executados pelo Banco do Nordeste, quanto aos seus impactos socioeconômicos e políticos? ${ }^{7}$.

Por uma abordagem etnográfica, a pesquisa avaliativa acompanhou a trajetória de dois programas de microcrédito do Banco do Nordeste, diferentemente tipificados no campo do microcrédito: o Crediamigo, do tipo microcrédito produtivo orientado; e o Programa de Apoio a Projetos Produtivos Solidário (PAPPS), inserido no campo das microfinanças solidárias.

Para tanto, realizou-se avaliação de caráter empírico e qualitativo, especificamente centrada na análise das representações dos funcionários de distintos níveis hierárquicos do Banco do Nordeste e dos beneficiários dos dois programas, visando formular indicadores de impactos de cada um desses.

Este artigo está dividido por itens, em que faremos: (1) a descrição da metodologia da avaliação; (2) a apresentação dos resultados e das análises da avaliação do Programa Crediamigo; (3) a apresentação dos resultados e das análises do PAPPS; (4) considerações finais acerca de pontos da avaliação dos programas.

\section{A metodologia da avaliação}

A etnografia, como procedimento metodológico de natureza qualitativa, permite apreendermos as representações, a visão de mundo e a perspectiva dos atores envolvidos nesses programas. Tratou-se de realizar, nos termos de Geertz ${ }^{8}$, uma "descrição densa", uma etnografia na qual se busca interpretar os diferentes significados acionados publicamente pelos atores à ideia de microcrédito, sentidos elaborados nas ações dos programas.

Imersos nesta perspectiva, acompanhamos a trajetória do Crediamigo e do PAPPS, com inspiração conceitual na noção de trajetória de Bourdieu ${ }^{9}$, partindo-se da ideia de que os programas não têm um sentido único e estão circunscritos a ressignificações quanto aos seus impactos realizadas pelos distintos atores envolvidos, segundo seus vários posicionamentos nos contextos em que percorre o programa ${ }^{10}$.

Para tanto, a construção da pesquisa etnográfica utilizada na avaliação dos programas envolveu as seguintes etapas:

- Pesquisa bibliográfica sobre microcrédito e microfinanças, desenvolvimento, dentre outras temáticas, com consulta na base de dados disponíveis na Internet, em sites do IBGE, BNDES, IPEA, DIEESE, BNB, Banco Central, bem como em sites especializados que abordam as temáticas; 
- Coleta de material institucional sobre os programas (desenho, objetivos, características, dados quantitativos de investimentos e de desempenho e seus impactos nas comunidades locais);

- Mapeamento estatístico dos programas no bairro pesquisado de Fortaleza;

- Entrevistas qualitativas com os atores institucionais, que conceberam e executam os programas na cidade, abordando os objetivos, conceitos centrais, inspiração teórica, metodologia e avaliação dos programas;

- Aplicação de questionários a beneficiários, com o intuito de traçar dados acerca do perfil socioeconômico dos beneficiários, tais como sexo, idade, estado civil, localidade de origem, orientação religiosa, profissão, situação econômica e familiar e qualificação profissional, numa perspectiva comparativa anterior e posterior ao empréstimo recebido;
- Observação participante nos loci das experiências gestadas pelos programas, com a verificação da vida familiar e do empreendimento de trabalho gerado pelo microcrédito;

- Histórias de vida dos beneficiários, escolhidos a partir dos perfis dos questionários, e sua vinculação com os programas ${ }^{11}$.

Apresentamos, nos itens que seguem, os resultados e a análise da avaliação dos programas Crediamigo e PAPPS.

\section{O Programa}

Crediamigo

Iniciou-se com um projeto piloto em 1997, passando efetivamente a operar em 1998 com a abertura de 45 unidades, e atualmente está presente em toda a área de atuação do Banco do Nordeste (os nove estados da região, o norte de Minas Gerais e do Espírito Santo, além das cidades Belo Horizonte e Rio

6 Uma versão preliminar deste artigo foi apresentada no V Seminário da Rede Brasileira de Monitoramento e Avaliação, realizado na UNICAMP, em setembro de 2013.

7 Para maior conhecimento dos resultados dessa avaliação, remetemos a: Almeida, 2012; Gussi, Santos Filho e Almeida, 2012; Silva, 2010; e Thé e Pereira, 2012.

8 GEERTZ,1989.

9 BOURDIEU, 1986.

10 Para maior detalhamento da proposta metodológica, remetemos a Gussi (2008).

11 Para aprofundamento metodológico sobre a técnica de história de vida e suas possibilidades na pesquisa social, remeto a Gussi (2005).

Revista Brasileira de Monitoramento e Avaliação | Número 6 | Julho-Dezembro de 2013 
de Janeiro). O programa tem por finalidade fornecer pequenos empréstimos de $\mathrm{R} \$ 100$ a R\$ 6 mil, de acordo com a necessidade e o porte do negócio, realizando-se de forma não burocrática para que microempreendedores financiem seus negócios em troca do chamado "aval solidário", que consiste em uma garantia, oferecida pelo empréstimo, em nome de um grupo formado para tanto, de maneira que o crédito não é fornecido individualmente, mas há a oferta de empréstimos a grupos de pessoas que se responsabilizam solidariamente por seu pagamento.

O seu público-alvo, sobretudo o de baixa renda, é constituído por autônomos, donos de pequenos negócios e trabalhadores informais que necessitam de crédito para gerar fonte de renda, no setor da indústria (mercearias, sapatarias, artesanato etc.), do comércio (mercadinhos, armarinhos, farmácias etc.), ou de serviços (salões de beleza, borracharias, oficinas mecânicas). Notadamente, os empréstimos concedidos são destinados à formação capital de giro, pelo produto "Giro Solidário", à aquisição de máquinas, equipamentos e realização de reformas.

Atualmente, após quinze anos de atuação, os resultados sobre o Crediamigo, divulgados pelo BNB, indicam: um aumento sempre crescente nas contratações e nos clientes ativos do Programa; que uma grande parte dos empréstimos tem sido destinada ao "Giro Solidário" de sua carteira ativa; que a maior quantidade de empréstimos é destinada às mulheres $(62,35 \%)$, e, finalmente, que o estado do Ceará apresenta-se como o maior beneficiado e com um maior número de clientes do Crediamigo (cerca de $1 / 3$ destes) ${ }^{12}$.

\subsection{O CREDIAMIGO NO BANCO DO NORDESTE}

Como o objetivo da avaliação do Crediamigo parte da busca de compreender os significados acerca da ideia de crédito e desenvolvimento, atribuídos pelos atores institucionais e beneficiários que se vinculam às ações dos programas, realizamos o acompanhamento do Programa em seu contexto institucional. Este processo foi realizado em duas frentes, delineadas pelo método etnográfico: uma vinculada à pesquisa por meio do acompanhamento e descrição de eventos institucionais do Banco do Nordeste com referência explícita e/ou implícita ao Programa Crediamigo ${ }^{13}$; outra, em uma vertente de observação das representações e significados dados no discurso de onze funcionários do Banco do Nordeste, de diferentes áreas, sobre o Crediamigo e visões particulares sobre desenvolvimento, em correlação às ações do próprio Banco do Nordeste. Apresentamos, sucintamente, os resultados dessas duas frentes de pesquisa.

\section{A) DESCRIÇÃO DE EVENTOS}

Observamos dois importantes eventos institucionais, a saber, o XVIII Fórum Banco do Nordeste de Desenvolvimento e o lançamento de um apêndice de um programa já existente, o Agroamigo, na figura do Agroamigo Mais ${ }^{14}$.

O primeiro ocorreu nos dias 19 e 20 de jutho de 2012, com a temática dos 60 anos da criação do Banco do Nordeste, representada pela frase "60 anos de Desenvolvimento". Dentro das falas dos representantes institucionais, houve repetidas referências sobre 
os programas de microfinanças creditícias do Banco do Nordeste, Crediamigo e Agroamigo. Em destaque, foi feita uma mesa voltada exatamente para ambos os programas, em que, ao discorrer o Crediamigo, demonstrou sua posição estratégica para o Banco, nesse momento, na afirmação da ampliação do crédito, da bancarização progressiva dos clientes e a solidariedade à população de baixa renda, sob uma ótica mercadológica.

O segundo ocorreu no dia 1 de março de 2013, durante o Encontro de Coordenadores (de Crédito) 2013, com o novo lema do programa: "Agroamigo, Parceiro do Brasil para um país sem miséria". Neste evento, houve a fala do diretor de Gestão do Desenvolvimento que colocou o microcrédito como a atual estratégia fundamental de desenvolvimento, tomando-o como catalisador da inclusão financeira e bancária. Ainda, foi ratificada a conexão entre as ideias de sucesso de mercado e a de desenvolvimento na premiação de assessor de crédito com maior número de contratações, reembolsos e clientes ativos. Na ocasião, o presidente do Banco do Nordeste reportou à vinculação do Banco ao projeto do
Governo Federal, Brasil Sem Miséria, sendo que o ministro do Desenvolvimento Agrário reafirmou o papel do Banco como parceiro e fomentador do desenvolvimento. Finalizou-se o evento com o lançamento do Agroamigo Mais, reafirmando a legitimidade do desenvolvimento na perspectiva do cliente, no exemplo de dois que assinaram contratos no novo formato do Agroamigo.

Esses eventos demonstram a centralidade do Programa Crediamigo como estratégia central na proposta de desenvolvimento do Banco no atual contexto político-institucional, atrelado, de um lado, a programas federais de erradicação da pobreza e, de outro lado, à estratégia de ampliação de mercado do próprio Banco.

\section{B) REPRESENTAÇÕES DOS ATORES INSTITUCIONAIS}

Investigamos os significados atribuídos ao crédito e ao desenvolvimento pelos funcionários do banco, por meio de entrevistas em profundidade, em que se colocou em pauta o relato pessoal de vida dentro do Banco do Nordeste, o próprio Banco e sua história ins-

12 http://www.bnb.gov.br

13 Para aprofundamento no método de análise de eventos, remetemos à Gluckman (1987) e Van Velsen (1987).

14 O Agroamigo, criado em 2005, é o Programa de Microfinança Rural do Banco do Nordeste, operacionalizado em parceria com o Instituto Nordeste Cidadania (INEC) e o Ministério do Desenvolvimento Agrário (MDA), destinado a agricultores familiares, enquadrados em algumas linhas de financiamento do Programa Nacional de Fortalecimento da Agricultura Familiar (PRONAF) https://www.bnb.gov.br/content/aplicacao/Produtos_e_Servicos/agroamigo/gerados/apresentacao.asp.

Revista Brasileira de Monitoramento e Avaliação | Número 6 | Julho-Dezembro de 2013 
titucional, bem como suas visões de desenvolvimento no Banco e a atuação deste no microcrédito e nas microfinanças.

Nesses discursos, observamos uma localização institucional dos programas de microcrédito do Banco associados aos programas sociais de transferência de renda do Governo Federal, tais como Bolsa Família e Brasil Sem Miséria, em que ambos atendem à base da pirâmide social brasileira, especialmente Crediamigo. Além disso, podemos observar diferentes lugares de fala sobre o desenvolvimento, dentro do Banco, com formas distintas de interpretar as estratégias de cunho mercadológico e social, escolhidas pelo Banco durante a história e no atual contexto. Nos discursos, concluímos que há um embate de visões dos funcionários quanto à posição institucional do Banco do Nordeste entre ser um banco de mercado e ser um banco de desenvolvimento social. Como será visto, essas representações circunscrevem os impactos do Crediamigo.

\subsection{OS BENEFICIÁRIOS DO CREDIAMIGO}

Como parte da pesquisa avaliativa do Crediamigo, realizamos em 2010 uma pesquisa dos impactos socioeconômicos do programa, tomando como amostra clientes que ingressaram há pelo menos três anos, localizados na jurisdição de uma Unidade do Banco do Nordeste, no Bairro Montese, na cidade de Fortaleza $^{15}$. O público-alvo da pesquisa foi o universo de 47 clientes, classificados pelo Banco, em 2006, como de baixa renda, com avaliação patrimonial menor que R\$ 1 mil.
O perfil socioeconômico dos beneficiários revelou que $94 \%$ eram do sexo feminino, destacando-se a evidência do recorte de gênero nas atividades de microcrédito. Em relação à idade dos participantes, $45 \%$ se encontravam na faixa etária compreendida entre 36 e 50 anos, enquanto que $29 \%$ tinham entre 51 e 65 anos, sendo que $67 \%$ dos entrevistados estavam casados ou em união estável, representando um acréscimo de 4,5\% na mesma condição de estado civil, em relação ao tempo de ingresso no Programa. Sua escolaridade apresenta-se da seguinte forma: $43,75 \%$ possuem nível de escolaridade médio, 50\% possuem nível fundamental e 6,25\% são analfabetos.

Desse perfil, depreende-se que o Crediamigo atinge, nessa faixa de renda, a trabalhadora informal, de meia idade, casada, excluída do mercado de trabalho formal. Esse perfil coaduna-se à situação do mercado de trabalho da cidade de Fortaleza que, segundo dados do Instituto de Desenvolvimento do Trabalho (IDT), Dieese e Fundação Sead, mais da metade da população da cidade trabalha na informalidade, sendo que, em sua grande maioria, esses trabalhadores informais são mulheres, acima de 40 anos e com Ensino Fundamental, muitas delas trabalhando como empregadas domésticas.

Ao recorrer ao Crediamigo, essas mulheres pretendem prover ou ampliar sua renda, ainda nos quadros das atividades informais, geralmente como comerciantes de cosméticos e alimentos, cabeleireira e manicure, e costureiras, algumas delas pretendendo mudar sua categoria de trabalho, sobretudo as que vivem do emprego doméstico. 
Na amostra da população escolhida, foi realizada uma investigação sobre suas condições de vida postas em relação ao período de tempo em que esses clientes obtiveram o empréstimo do Crediamigo sob as seguintes variáveis: trabalho, renda, associativismo, educação e qualificação profissional, domicílio e família, saúde e lazer.

Na ocasião da pesquisa, 97\% utilizavam somente recursos do Crediamigo para executar suas atividades laborais, obtendo o acesso ao crédito por meio do aval solidário, com a formação de pequenos grupos. Em relação aos valores de empréstimos, 66\% dos clientes entrevistados contrataram empréstimos na faixa compreendida entre R\$ 200 e R\$ 1 mil, enquanto que, para 34\%, o valor varia entre $\mathrm{R} \$ 1$ mil a R\$ 1,5 mil. Verifica-se também a evolução da faixa de empréstimos para esses clientes em que $78 \%$ deles já realizaram, em média, nove empréstimos no Programa, no período considerado. Os recursos são utilizados em $94 \%$ dos casos para a compra de mercadorias e matéria-prima, representando o capital de giro para a realização das atividades laborais ${ }^{16}$.

\subsection{AVALIAÇÃO DO PROGRAMA CREDIAMIGO}

A análise dos resultados da pesquisa avaliativa sobre o Crediamigo aponta o programa como impactante na renda dos clientes, ampliador do crédito nas classes mais baixas, assim como um catalisador da ampliação e mudança do perfil laboral e de renda.

Apesar desse quadro, a condição de vida desses clientes permaneceu estável, alterando-se apenas a condição de consumo doméstico das famílias envolvidas, não havendo mudança significativa em outros aspectos da vida, tais como escolaridade, capacitação profissional, moradia, saúde e lazer. A apreensão dessas necessidades surge nos clientes no momento em que se afirma, de um lado, a cidadania a partir da inclusão pelo consumo, mas, de outro, aponta para a necessidade de um maior aprofundamento da política por meio de capacitação para o trabalho, qualidade de informação e conhecimento para as atividades e a melhoria das condições de vida em geral, para além do consumo.

15 Para um maior detalhamento dessa avaliação de impacto junto a esses clientes, remetemos à dissertação de Silva (2010).

16 Com o intuito de aprofundar qualitativamente nossa avaliação sobre os impactos do Crediamigo, recuperamos a trajetória de quatro clientes no programa Crediamigo por meio de suas histórias de vida. Foram realizadas entrevistas junto aos clientes A.A. e M.E., I.B.F. e M.L., escolhidos aleatoriamente entre os demais que participaram da pesquisa. Para maior aprofundamento sobre os resultados e a análise dessas trajetórias para a avaliação do programa, remetemos a SILVA, 2010; THÉ e PEREIRA, 2012; e THÉ, 2013.

Revista Brasileira de Monitoramento e Avaliação | Número 6 | Jullo-Dezembro de 2013 
Aos resultados da pesquisa inferem a ideia de desenvolvimento dentro da qual o Crediamigo está inscrito no Banco do Nordeste. Qual seja: o Crediamigo orienta-se, primeiramente, para a dimensão econômica, com foco no aumento da renda e do consumo dos beneficiários, implicando um desenvolvimento vinculado à inclusão laboral, ao consumo individual e o efeito indireto no próprio mercado.

De outro lado, observam-se representações dos sujeitos institucionais em que se encontram interpretações vigentes e conflitantes dentro da instituição, acerca do Crediamigo e do próprio banco. Particularmente, nelas é possível referenciar a importância, tanto para a pesquisa quanto para os próprios sujeitos, da ideia de desenvolvimento, no entendimento de que a instituição é um banco de desenvolvimento.

Nesse caminho, esses sujeitos compreendem o Programa Crediamigo como aquele que mais representa a imagem atual do Banco, por ser o programa com mais clientes e o mais reconhecido, tornando-se a principal estratégia institucional de desenvolvimento para um grande setor da economia nacional e regional, o setor informal.

Outro ponto importante do Crediamigo, dentro da ótica dos sujeitos institucionais no Banco do Nordeste, é seu significado como inflexão para uma mudança institucional, composta por dois matizes: um vinculado à entrada e à mudança de vida do cliente no programa, com um viés mercadológico de sucesso, envolvendo a bancarização, o aumento de renda e do faturamento; e o segundo, que entende a mudança como progressão nos perfis de clientes, em que pese o crescimento do empreendimento, tendendo o cliente a passar de Crediamigo Comunidade para Crediamigo Giro Solidário e, deste, para o Crediamigo Individual, até que o faturamento do empreendimento supere $\mathrm{R} \$ 60 \mathrm{mil} / \mathrm{ano}$ e o cliente esteja apto a subir na pirâmide dos programas do Banco para Micro e Pequena Empresas.

Este segundo matiz, na verdade, apresenta-se de forma geral entre os programas do Banco do Nordeste, na visão institucional, como forma de angariar clientes em uma faixa de renda e promover seu crescimento de faturamento e, portanto, de renda, a partir de serviços bancários que antes não poderiam obter, havendo um processo de crescimento econômico dentro de uma lógica de mercado, enquanto que os impactos sociais são postos em segundo plano, pois são entendidos como decorrência do primeiro. Ou seja, para as interpretações dos sujeitos institucionais, a bancarização é o primeiro passo do cliente para sua entrada no mercado e para o crescimento e desenvolvimento, do ponto de vista mercadológico, em que mesmo a lógica solidária é instrumentalizada para a lógica de mercado.

Quanto aos clientes, suas narrativas relataram mudanças ocorridas em suas vidas após sua inserção no Programa e o que eles veem de aspectos positivos e negativos, expressando o que o Crediamigo lhes oferece, não somente para seu próprio trabalho, mas para os clientes do Banco em geral, além de indicarem o que poderia melhorar. Tais aspectos 
mostram-se importantes, pois, por meio deles, os clientes manifestaram suas representações, visões, versões, inversões e perspectivas sobre o Programa, em relação às suas próprias histórias de vida, o que possibilita refletir tanto sobre os impactos do Programa.

As narrativas dos clientes elucidam a oportunidade que o programa de microcrédito oferece a seus clientes, a de conseguirem um empréstimo com baixas taxas de juros, algo que outros bancos não thes possibilitam, facilitando para que possam montar um negócio próprio e/ou dar continuidade a este e podendo, assim, ter uma fonte de renda que se revela como alternativa para aqueles que não estão inseridos no mercado formal de trabalho. Por outro lado, por meio de algumas críticas a determinados pontos do Programa, ou até mesmo do silêncio gerado após perguntas sobre os aspectos negativos desse, percebemos que os clientes consideram que o Crediamigo tem limites e não satisfaz completamente suas necessidades sociais.

\section{O programa de apoio a Projetos Produtivos Solidários - PAPPS}

O PAPPS, no Banco do Nordeste, teve início em 2005, mediante convênio com a Secretaria Nacional de Economia Solidária (Senaes), do Ministério do Trabalho e Emprego, para estabelecer parcerias na execução de programa de apoio a organizações que operam com Fundos Rotativos Solidários - FRSs. ${ }^{17}$

O marco legal do Programa foi definido por Decreto da Presidência da República no 94.386, de 28.05.1987, regulamentado pela Resolução no RD/5162, em 23 de dezembro de 2003, que disponibiliza recursos não reembolsáveis, oriundos do Banco do Nordeste/Fundo de Desenvolvimento Regional (FNE), para apoiar instituições que introduzam fundos rotativos solidários, projetos associativos e comunitários de produção de bens e serviços situados nos estados da área de atuação do Banco.

O PAPPS, em seus próprios termos, define-se como uma estratégia diferenciada e autossustentável do Banco do Nordeste, para beneficiar diretamente as comunidades rurais e urbanas, contribuindo para sua emancipação social e econômica a partir da afirmação da solidariedade. Partindo disso, os FRS, ao fornecerem financiamento, consideram a possibilidade de que o dinheiro aplicado nas atividades possa produzir efeito e ser devolvido a fim de beneficiar outros participantes ${ }^{18}$.

Em 2005, o Banco, em parceria com a Senaes e a Rede de Socioeconomia Solidária (RSE), lançou o primeiro edital público do PAPPS, para seleção de projetos a serem apoiados. 
Em 2008 e 2010, foram lançados outros editais para toda a Região Nordeste. Em 2011, foi publicado edital para a Bahia ${ }^{19}$. O edital de 2011, de R\$ 1 milhão, com outras contratações, atingiu a cifra de RS 8 milhões, distribuídos por mais de 84 projetos. Os estados da Bahia, Ceará e Pernambuco concentram 61\% das aplicações, sendo que, no período de 2005 a 2009, Ceará e Pernambuco, como os estados com maior número de projetos, receberam maior volume de recursos, de $\mathrm{R} \$$ 989.003,00 e R\$1.012.395,00, respectivamente.

Dentre os projetos apoiados em 2008, destaca-se a destinação de recursos para a formação do FRS da Rede Bodega, nos municípios de Aracati, Fortaleza, Sobral e Tianguá, no Ceará. Integrante da Rede Bodega, a Associação das Mulheres em Ação (AMA/Budeg'AMA) recebeu parte desses recursos, para ser utilizada na criação do FRS, destinado à produção e comercialização das associadas, cujos impactos foram objeto de nossa pesquisa avaliativa, tomado como estudo de caso para a análise do PAPPS no Banco do Nordeste.

\subsection{A EXPERIÊNCIA DA REDE BODEGA E A AMA/BUDEG'AMA ${ }^{20}$}

Em 2004, a Cáritas Regional do Ceará criou o projeto Rede Bodega, objetivando fomentar ações de produção e comercialização dos produtos dos grupos e comunidades, por meio dos FRS, a consolidar práticas de economia popular solidária no Ceará. As quatro unidades regionais dessa Rede, no Ceará, constituem espaços de comercialização coletiva e autogestionária da produção a partir do contexto de enfrentamento das problemáticas comuns aos grupos produtivos, relativas às dificuldades de comercializar os produtos, frente ao mercado socioeconômico explorador e excludente (Relatório Projeto Rede Bodega 2008-2010).

Em seu início, a Rede contava com a participação de 13 grupos. Dados de 2010 mostram 50 grupos associados, estabelecidos em 13 municípios das regiões do baixo e médio Jaguaribe, litoral e região serrana do Limoeiro do Norte, Sobral e Tianguá (hoje em Viçosa do Ceará). É composta por: Bodega Nordeste Vivo e Solidário, em Aracati; Budega do Povo, em Tianguá; a recém-criada Bodega Arcos, em Sobral; e a Associação das Mulheres em Ação (AMA/ Budeg'AMA), situada no bairro Conjunto Esperança, da periferia de Fortaleza, caso aqui avaliado (Relatório Projeto Rede Bodega 2008-2010).

Nesse formato, a Rede acessou o crédito público ao ser aprovada na seleção feita pelo PAPPS, possibilitando a criação de um FRS para as bodegas, entre elas a AMA/Budeg'AMA. Esta foi criada em 1999, reunindo vinte e duas mulheres da Região Metropolitana de Fortaleza e de bairros circunvizinhos ao Mondubim a partir de um curso de alfabetização de adultos, ministrado e apoiado pela Cáritas Regional do Ceará. As demais associadas entraram via pastorais sociais da Igreja Católica ou movimentos da própria comunidade.

Com a necessidade de obter mais recursos para produção e encontrar meios de estruturar a comercialização, em 2007, a AMA passou a fazer parte da Rede Bodega, adotando, a partir daí, o nome fantasia Budeg'AMA, a Bodega da AMA, ou a loja da AMA, onde comercializam os produtos. Além dos produtos 
confeccionados pelas associadas, a associação Budeg'AMA também vende produtos de outras três unidades da Rede Bodega (Aracati, Sobral e Viçosa do Ceará).

A efetiva participação na AMA/Budeg'AMA requer um esforço adicional por parte de suas associadas em atividades, tais como: expediente na loja um dia por semana; participar, mediante rodízio, das reuniões mensais da rede socioeconômica solidária; produzir coletivamente uma vez por semana (aos sábados); contribuir, quando necessário, com parcelas mensais para a manutenção das despesas de aluguel, água e energia da sede. Desta forma, nem todas as associadas puderam ou quiseram contribuir para o funcionamento da Budeg'AMA. Contudo, como será visto, os dados coletados mostram que a AMA tem favorecido a produção coletiva, antes produzida individualmente, com laços afetivos fortalecidos, comprovando a dimensão social, que embasam pressupostos da economia solidária.

Na pesquisa avaliativa, procuramos traçar o perfil socioeconômico das associadas da Budeg'AMA, com escolaridade, moradia, vida profissional, renda recebida na associação, despesas e condições de vida e de trabalho, bem como a utilização dos recursos do PAPPS para a composição do FRS da própria AMA.
Assim, das dez mulheres entrevistadas, a maioria é de casadas ou viúvas, com 70\% das primeiras, e as idades vão de 41 a 67 anos, com 50\% acima de 60 . Quanto à escolaridade, observa-se que 60\% fizeram o Ensino Médio, completo e incompleto, sendo que $60 \%$ frequentam cursos, seja do ensino formal, seja do informal. Uma faz curso superior.

Quanto à moradia, 70\% possuem casa própria, adquirida antes da AMA. No compartilhamento da moradia, há um equilíbrio: $40 \%$ moram com marido e filhos. Computando-se as que moram com marido, filhos, netos, as que residem com marido, filhos e cunhados e as que habitam com marido, filhos e pais, sobe para $80 \%$.

No tocante à vida profissional, o trabalho com carteira assinada, durante o período da vida laboral anterior à entrada na AMA, mostra que $40 \%$ tiveram carteira assinada e 60\% nunca tiveram, com vidas profissionais direcionadas ao trabalho informal, seja por falta de oportunidade, seja por opção.

Em relação ao trabalho atual na AMA, 60\% o realizam na própria sede, os outros $40 \%$ trabalham em casa. Isso porque o trabalho na sede geralmente é realizado pelas mulheres que fazem parte da Budeg'AMA. As demais optaram por não comercializar seus produtos

20 Para um maior detalhamento dessa avaliação de impacto do PAPPS junto às associadas da Bodeg'AMA, remetemos à dissertação de Almeida (2012).

Revista Brasileira de Monitoramento e Avaliação | Número 6 | Julho-Dezembro de 2013 
na loja para não ter que contribuir com as despesas da sede, já que estas comprometem os ganhos, que não são muitos. Na participação em outras atividades remuneradas, além da realizada na AMA/Budeg'AMA, 80\% responderam não ter outra ocupação, demonstrando que a AMA é o principal local de produção.

Finalmente, quanto à renda com o trabalho na AMA/Budeg'AMA e renda familiar: a renda auferida na atividade da AMA para 60\% varia de R\$ 100 a R\$ 200 por mês, com ganho ainda diminuto. A composição da renda familiar, além daquela gerada pelo trabalho na AMA/ Budeg'AMA, 70\% complementam a manutenção da casa com o marido, as demais complementam com a pensão, no caso das viúvas.

Na renda gerada no trabalho da AMA, percebe-se a não suficiência para manter a vida laboral. Os resultados mostram despesas maiores que receitas. Ao tomar a média de ganhos de R\$ 200 mensais, os dados mostram as despesas alcançando o triplo. Mas entende-se que os ganhos contabilizados não se limitam apenas ao plano material, como se verá adiante, salientando os ganhos, de valores não mensuráveis, na vida social e na perspectiva política.

Partindo desse perfil, aprofundamos a dimensão qualitativa da avaliação em que procuramos conhecer: de um lado, a visão de cada associada sobre os recursos do PAPPS e as modificações, acaso percebidas, a partir de sua aplicação na AMA, bem como a importância para manter do empreendimento; de outro lado, a visão sobre o PAPPS dos gestores do Banco do Nordeste.

\subsection{AVALIAÇÃO DO PAPPS}

\subsubsection{NA VISÃO DAS PARTICIPANTES DA AMA/BUDEG'AMA}

No intuito de conhecer a visão das associadas sobre modificações ocorridas em suas vidas e na vida da AMA/Budeg'AMA a partir do recebimento dos recursos do PAPPS, procurou-se analisar sua compreensão acerca desse aporte e o que ele representa. Desta forma, consideramos, nessas visões, as dimensões social, econômica, política e ambiental para avaliar o impactos do PAPPS, apresentadas a seguir.

(a) Dimensão social: configurada pelos FRSs, volta-se para as relações solidárias, capazes de motivar a inclusão e o crescimento coletivo. Fazendo um comparativo entre a vida dessas mulheres antes e depois da AMA, percebe-se a importância das mudanças. Se antes só viviam para a família, com a adesão à AMA puderam se sentir úteis e galgar um novo patamar de vida e de respeito na própria família, a partir de uma renda extra, gerada pelo trabalho realizado.

(b) Dimensão econômica: os pressupostos do FRS visam proporcionar a geração de renda, mediante fortalecimento dos elos da cadeia: produção, beneficiamento e comercialização dos produtos. Sobre o aporte de recursos do PAPPS na AMA/Budeg'AMA, há uma unanimidade em considerá-lo positivo, pois a partir dele foi possível a formação do FRS para aquisição de insumos para produção. Porém há dúvida e preocupação com relação à dependência criada ao fundo. Além disso, concordam que é necessário um retorno financeiro maior, e deve ser buscado. 
(c) Dimensão política: no enfoque dos FRSs, pressupõe a existência de semelhantes interesses, bem como deve levar à partilha solidária de bens e resultados, incluindo a autogestão, em que deve haver comprometimento e participação. Assim, sobre a organização, a forma de divisão dos ganhos e a gestão da associação há um reconhecimento de que a AMA amplia a participação, no momento em que procura envolver todas as associadas nas decisões a serem executadas, fortalecendo a autogestão. Com relação à divisão dos ganhos, percebe-se uma consciência coletiva para o exercício da transparência na apuração das sobras, capaz de fazer que os ganhos sejam repartidos de forma equânime.

(d) Dimensão ambiental: nos FRSs procura-se despertar a conscientização do uso dos recursos naturais, na produção e no consumo, de modo a respeitar o meio ambiente e garanti-los para as próximas gerações. Assim, na prática, as participantes foram unânimes em garantir que há o respeito e a consciência para uma produção mais limpa, procurando utilizar, principalmente na confecção de artesanato, material reciclável.

\subsubsection{NA VISÃO DOS GESTORES DO BANCO DO NORDESTE}

Como contraponto comparativo e em relação às associadas, a fim de se construir o estudo avaliativo, consideramos a visão de gestores do Banco do Nordeste, que trabalham diretamente com o PAPPS, nas mesmas dimensões avaliativas consideradas, a que se chegou aos seguintes resultados:

(a) Dimensão Social: motivação para o coletivo e a prática de relações solidárias. Esses aspectos podem contribuir para o fortalecimento dos empreendimentos de economia solidária, levando-se em conta que podem aproximar as pessoas e fazer que elas se motivem em busca de um ideal comum.

Atuando de forma indireta ou direta, os representantes reconhecem a importância da solidariedade para o fortalecimento das relações entre cooperados e associados. Admitem que haja mudança social e que o PAPPS desempenha papel fundamental nesse processo.

(b) Dimensão econômica: observam que o aporte causa impacto por trazer benefícios econômicos e sociais, assim como contribui, de forma muito acentuada, para o desenvolvimento local. Sobre a avaliação que fazem dos recursos hoje destinados pelo Banco do Nordeste ao PAPPS, um representante acredita serem satisfatórios os resultados e que os recursos são bem aplicados, enquanto outro entende que o aporte não é tão grande, e que isso deve despertar nas pessoas beneficiadas uma vontade de buscar recursos de outros programas do banco, a exemplo do microcrédito.

(c) Dimensão política: procura inserir a prática da partilha solidária, bem como da autogestão, em que deve haver comprometi-

Revista Brasileira de Monitoramento e Avaliação | Número 6 | Julho-Dezembro de 2013 
mento e participação de todos no processo decisório. Em depoimentos dos representantes, coloca-se em destaque a cooperação e a cidadania que afloram a partir do FRS, sendo um dos grandes benefícios o fato de haver reunião e maior discussão sobre os rumos.

(d) Dimensão ambiental: desejando despertar para uma produção e para um consumo conscientes percebe-se que nas obrigações inseridas para obtenção do PAPPS, é necessário que o projeto apresente suas pretensões em relação à prática produtiva e que seja demonstrado esse cuidado com as questões que se relacionam ao cunho ambiental.

Os resultados da pesquisa demonstram que, se do ponto de vista econômico os recursos do PAPPS, aplicados na AMA/Budeg'AMA, não garantem a continuidade do empreendimento para que se mantenha autossustentável ao longo do tempo, contudo pode-se considerar que o PAPPS causou e continua a causar impactos nas demais dimensões social, política e ambiental. Nota-se que o impulso fornecido ao empreendimento, a partir da formação do FRS, aumentou a autoestima das associadas, o fortalecimento dos laços afetivos, o aumento da autonomia, o crescimento pessoal e aumentou a noção de cidadania, voltada para a consciência dos direitos, sendo fortalecida a vertente política e social da AMA, mais do que a econômica.
Resta saber em que medida isso pode fragilizar os empreendimentos e colocar em risco o Programa, pois a ideia de desenvolvimento proposta pelo PAPPS, atrelada somente a impactos mais visíveis nas dimensões social, política e ambiental, pode estar comprometida se não houver o fortalecimento da gestão dos FRSs, incluindo aí um maior volume de recursos.

\section{Considerações finais}

Como conclusões da avaliação dos programas, faz-se necessário: (1) a compreensão sobre as relações entre as interpretações dos beneficiários e dos sujeitos institucionais, gestores ou não, de ambos os programas, o Crediamigo e o PAPPS e (ii) uma avaliação comparada entre os programas.

(i) Em relação ao Crediamigo, a comparação entre as interpretações dos clientes e dos sujeitos institucionais se pauta pelo trânsito entre duas lógicas, a de solidariedade e a do mercado: a primeira, para os clientes, percebe-se como difícil se manter, pelo peso da dívida contraída pelo Crediamigo e pela cobrança mútua entre eles, enquanto que, para os sujeitos institucionais, a lógica da solidariedade constituiu-se como utilitária para a articulação instrumental de uma estratégia bancária do programa para se garantir o crédito. 
Quanto à lógica do mercado, as visões se encontram no reconhecimento processo de bancarização, via Crediamigo, que oferece ao cliente serviços bancários e, para os atores institucionais, que a compreende a partir da inserção das pessoas do mercado. Em outro ponto, clientes aproximam o Crediamigo a formulações de desenvolvimento socioeconômico, notando que o programa leva a uma ampliação da renda, ainda que haja uma estagnação em indicadores de desenvolvimento social, enquanto os sujeitos institucionais observam o crescimento financeiro do empreendimento e seu possível crescimento na escala dos programas do Banco, entendendo a dimensão social do Crediamigo, como consequência da ampliação de renda.

Com relação ao PAPPS, comparando-se as visões dos sujeitos envolvidos, associadas da Rede Bodega e gestores do Banco do Nordeste, no que concerne às dimensões social, econômica, política e ambiental, temos que:

- na dimensão social, ambos os sujeitos consideram que ocorreram mudanças significativas e positivas na vida das associadas, como o aumento dos laços afetivos, que age como a força motriz para a produção ter continuidade;
- na dimensão econômica, há divergência entre as visões: enquanto as associadas observam que a renda gerada não é suficiente para uma autonomia econômica, para os representantes do Banco, o PAPPS tem promovido desenvolvimento por meio dos FRS;

- na dimensão política, ambos entendem que houve avanço significativo entre as associadas em questões referentes à autonomia, cidadania, entre outras.

- na dimensão ambiental, os discursos elucidam que existe consciência ambiental na produção da $A M A$, mas percebe-se que é um tema ainda em construção, acontecendo mais no discurso que na prática.

(ii) Com relação a uma avaliação comparada entre os dois programas, ressaltamos pontos da dimensão social e econômica, os impactos do Crediamigo e do PAPPS. Quanto ao último, a dimensão social tem como objetivo e consequência uma construção de afetividade, confiança e um sentido de solidariedade entre os membros do FRS, ou seja, a construção de um capital social, que é exigido e instrumentalizado no programa Crediamigo, mas ainda não efetivado entre os clientes. Enquanto a dimensão econômica, que indica os impactos do PAPPS, apresenta-se em segundo plano, dian- 
te das demais dimensões, no Crediamigo tem principal importância e fundamenta o programa.

Isso corrobora com a interpretação dos sujeitos para pensarmos uma comparação entre os dois programas: no PAPPS, há mudanças do capital social e das dimensões ambiental e política no escopo do Programa, mas há uma deficiência na dimensão econômica, quanto à geração de renda propriamente dita, enquanto que, no Crediamigo, há aumento na renda, nos moldes da reificação do mercado, atrelada à ideia de desenvolvimen- to econômico, mas é deixado de lado necessidades sociais dos clientes, demandadas pelo próprio aumento da renda.

Resta saber em que medida o PAPPS, residual no Banco do Nordeste em relação à atual projeção do Crediamigo, poderá se manter institucionalmente, mesmo que os resultados do primeiro, associados à afirmação de novos valores sociais e políticos, possam apontar encaminhamentos para a superação dos limites dos impactos do Crediamigo junto aos clientes, reduzidos ao pequeno aumento de sua renda. 


\section{Referências bibliográficas}

ALMEIDA, G. F. B. Avaliação dos impactos do programa de Apoio a Projetos Produtivos Solidários (PAPPS) na experiência de economia solidária da AMA/Budeg'AMA. 2012. 155f. Dissertação (Mestrado em Avaliação de Políticas Públicas) Universidade Federal do Ceará, Fortaleza, 2012.

BANCO DO NORDESTE DO BRASIL. Relatório Anual Crediamigo. Disponível em: www.bnb. gov.br. Acesso em: 13 fev. 2014.

BOURDIEU, P. A ilusão biográfica. In: Razões práticas: sobre a teoria da ação. Campinas: Papirus, 1996.

GEERTZ, G. A Interpretação das culturas. Rio de Janeiro, Zahar, 1989.

GONÇALVES, A.F.; GUSSI, A.F. Visões sobre o desenvolvimento e políticas públicas na Paraíba: os dilemas entre universalismo e particularismos. In. ANDRADE, M.O.; LIMA, G.F. (org). Gestão e desenvolvimento socioambiental na Paraíba: concepções e práticas. Paraíba: Editora UFPB, 2012, p. 47 a 71.

GLUCKMAN, M. Análise de uma situação social na Zululândia Moderna. In: FELDMAN-BIANCO, B. (Org). A antropologia das sociedades contemporâneas. São Paulo: Global, 1987.

GUSSI, A. F. Apontamentos teórico-metodológicos para avaliação de programas de microcrédito. Aval - Revista de Avaliação de Políticas Públicas. UFC, n. 1, p. 29-37, 2008.

Pedagogias da experiência no mundo do trabalho: narrativas biográficas no contexto de mudanças de um banco público estadual. 2005. 356f. Tese (Doutorado), Faculdade de Educação, Universidade Estadual de Campinas, Campinas, 2005.
GUSSI, A; SANTOS FILHO; C.S.; ALMEIDA, G.F. A experiência de fomento a fundos rotativos solidários no Nordeste: o caso da Rede Bodega. Mercado de Trabalho: Conjuntura a Análise. Ministério do Trabalho e Emprego - MTE. IPEA, ano 17, fevereiro de 2012, p. 77 a 86.

MOTA, J. R. D. Políticas públicas e economia solidária: avaliação do Projeto Sementes da Solidariedade. 2009. 96f. Dissertação (Mestrado em Avaliação de Políticas Públicas), Universidade Federal do Ceará, 2009.

Relatório Final do Projeto Rede Bodega: Constituindo Fundos de Produção e Comercialização Solidária - período de agosto de 2008 a julho de 2010.

SILVA, R. J. F. Avaliação dos impactos do programa Crediamigo em população de baixa renda de Fortaleza. 2010. 190f. Dissertação (Mestrado em Avaliação de Políticas Públicas) - Universidade Federal do Ceará, Fortaleza, 2010.

THÉ, R. F. S.; PEREIRA, J. E. O. Interpretando narrativas sobre microcrédito: histórias de vida de clientes do Crediamigo em Fortaleza. CAOS. Revista Eletrônica de Ciências Sociais, v. 21, novembro de 2012, p. 13-24.

THÉ, R. F. S. Microcrédito, Dádiva e Narrativas: Esboços interpretativos sobre o Programa Crediamigo por meio de histórias de vida. Sociais e Humanas, v. 26, n. 2, mai/ago 2013, p. 402-414.

VAN VELSEN, J. A análise situacional e o método de estudo de caso detalhado.

FELDMAN-BIANCO, B. (Org). A antropologia das sociedades contemporâneas. São Paulo: Global, 1987. 